\title{
Um relato de experiência de uso da informática na EMEB Eurípedes Brasil Milano
}

\author{
Mateus Henrique Dal Forno ${ }^{1}$, Amanda Meincke Melo ${ }^{1}$ \\ ${ }^{1}$ Universidade Federal do Pampa (UNIPAMPA) - Campus Alegrete \\ Av. Tiarajú, 810 - Ibirapuitã - 97.546-550 - Alegrete - RS - Brasil \\ mateusdalforno@alunos.unipampa.edu.br, amanda.melo@unipampa.edu.br
}

\begin{abstract}
Resumo. Programas de governo têm fomentado a adoção de tecnologias digitais em escolas públicas, provocando que comunidades escolares se organizem para que possam adotá-las em suas atividades cotidianas. Através de ações de extensão, Universidades podem colaborar à formação continuada de professores da Educação Básica e ao uso de tecnologias da informática em escolas públicas, ao mesmo tempo em que estudantes universitários têm a oportunidade de se desenvolverem profissionalmente. Este artigo realiza um relato de experiência de oficinas de informática, no ano de 2012, em uma escola pública municipal da fronteira oeste do Rio Grande do Sul no contexto do projeto de extensão "Info.edu: tecnologias da informação e comunicação em comunidades escolares de Alegrete” (MEC/SESu - PROEXT 2011). Os resultados evidenciam a relevância da interação dialógica Universidade-Escola, na formação de recursos humanos em ambos os espaços educacionais.
\end{abstract}

\begin{abstract}
Governmental programs have been promoting the adoption of digital technologies in public schools, causing educational communities to organize themselves to adopt these technologies in their daily activities. Through extension activities, universities can contribute to basic education teacher's training and to the use of computer technology in public schools, while college students have the opportunity to develope professionally. This paper presents an experience regarding basic computer classes, during 2012, conducted in a public school from South of Brazil in the context of the extension project "Info.edu: tecnologias da informação e comunicação em comunidades escolares de Alegrete" (MEC/SESu - PROEXT 2011). The results point out the relevance of University-School dialogical interaction in the development of human resources in both educational settings.
\end{abstract}

\section{Introdução}

Nos últimos anos o Governo Federal tem realizado investimentos em tecnologias digitais nas escolas, através de programas como PROINFO [Ministério da Educação b], Um Computador por Aluno (UCA) [Ministério da Educação c] e Banda Larga na Escola [Ministério da Educação a]. Na rede pública de ensino do estado do Rio Grande do Sul, recentemente o Governo Estadual lançou um projeto que distribui Tablets para professores [Secretaria da Educação do Estado do Rio Grande do Sul ]. Além do investimento em infraestrutura, entretanto, é necessária a formação dos professores e dos estudantes, para que utilizem de modo adequado e produtivo as tecnologias que estão cada vez mais pervasivas 
na sociedade, aproveitando amplamente suas possibilidades nas mais variadas atividades do cotidiano. Observam-se desafios em realizar a adoção dessas tecnologias pelos professores como ferramenta pedagógica e também como ferramenta inclusiva, especialmente no Atendimento Educacional Especializado (AEE) [Amanda M. Melo and Wernz 2012] [Melo and Pupo 2010].

O Grupo de Estudos em Informática na Educação (GEInfoEdu), do Campus Alegrete da Universidade Federal do Pampa (UNIPAMPA), desde o ano de 2010, realiza ações e projetos de formação de professores e de apoio ao uso das Tecnologias de Informação e Comunicação (TIC) em escolas públicas municipais e estaduais. Sua equipe é composta por discentes, docentes e técnicos administrativos da Universidade, além de representantes da comunidade externa.

Apresenta-se, neste artigo, relato de experiência do GEInfoEdu na realização do projeto de extensão "Info.edu: tecnologias da informação e comunicação em comunidades escolares de Alegrete" (MEC/SESu - PROEXT 2011) na Escola Municipal de Educação Básica (EMEB) Eurípedes Brasil Milano. O projeto, realizado em mais 03 escolas no município (duas da rede municipal e uma da rede estadual de ensino) e no Centro de Referência em Inclusão Digital (CRID), tinha como objetivo a inserção da informática no cotidiano das escolas participantes, contribuindo à formação de professores, à promoção da acessibilidade e à inclusão digital de membros dessas comunidades escolares. As atividades principais envolviam a oferta de oficinas pelos bolsistas do projeto - acadêmicos dos cursos de Ciência da Computação e de Engenharia de Software - nos educandários e no CRID, além do apoio às demais atividades de informática na educação desenvolvidas nesses espaços.

O restante do texto está organizado como segue. A Seção 2 apresenta o referencial teórico-metodológico, inspirado na pesquisa-ação [Thiollent 1996]. A Seção 3 traz um relato de experiência de oferta de oficinas de informática a membros da comunidade escolar da EMEB Eurípedes Brasil Milano. Finalmente, as Seções 4 e 5 apresentam, respectivamente, os resultados e as considerações finais do trabalho desenvolvido.

\section{Referencial Teórico-Metodológico}

O trabalho é inspirado na pesquisa-ação [Thiollent 1996], abordagem na qual investigadores e participantes envolvem-se de modo colaborativo e participativo no desenvolvimento das ações. Organiza-se em ciclos de "Planejamento - Ação - Observação - Reflexão". Dessa forma, a equipe de pesquisadores entra em contato com a realidade local e regional, desafiada a analisar situações-problemas de modo complexo e a atuar estrategicamente para transformar a realidade, em sintonia com as comunidades escolares. A cada ciclo, o aprendizado construído em ações anteriores colabora ao aperfeiçoamento de novas ações.

\section{Relato de Experiência}

Na EMEB Eurípedes Brasil Milano, as atividades foram desenvolvidas no ano de 2012, no turno da tarde, nos períodos de abril a junho e de agosto a outubro. As oficinas, cada qual com 04 horas de duração, aconteciam às segundas-feiras para professores, às quartas-feiras para estudantes e às quintas-feiras para a comunidade. Nas segundas e quintas-feiras das semanas em que não havia oficinas, realizava-se o apoio às demais atividades e a projetos de informática na educação da escola. 
O Laboratório de Informática, no qual a maioria das atividades foram realizadas, possuía 08 computadores multiterminais ( 2 terminais para cada gabinete) e um servidor, conectados à Internet, totalizando 17 computadores. O Sistema Operacional (SO) disponível era o Linux Educacional 4.0, desenvolvido especificamente para uso em Laboratórios de Informática de Escolas de Educação Básica. Esse SO possui nativamente vários aplicativos com fins educacionais, mantido pelo Centro de Computação Científica e Software Livre (C3SL) da Universidade Federal do Paraná ${ }^{1}$.

Os assuntos abordados nas oficinas, bem como seu cronograma de execução, foram definidos em comum acordo com a equipe diretiva da escola. A equipe do GEInfoEdu apenas sugeriu alguns temas, levando-se em consideração o incentivo à autonomia e à segurança no uso de tecnologias digitais pelos participantes, além de aspectos relacionados à acessibilidade e aos recursos de Tecnologia Assistiva (TA). Desse modo, organizaram-se as oficinas de acordo com a realidade e o interesse manifestado. Optou-se, na EMEB Eurípedes Brasil Milano, pelos seguintes assuntos: "Introdução à Informática", "Produção de Materiais Digitais", "Informática Acessível e Recursos de Tecnologia Assistiva", "Recursos da Web 2.0", "Construção de Sites", "Produção Acessível" e "Desenvolvimento de Soluções Tecnológicas para o Contexto Escolar e Comunitário".

Periodicamente, às terças-feiras à tarde, os bolsistas do projeto reuniam-se com a coordenação do projeto para socializarem suas experiências e desafios encontrados no desempenho de suas atividades, além de realizarem o planejamento das atividades subsequentes. Desse modo, a coordenação do projeto acompanhava o projeto e auxiliava na resolução de problemas em contato com outras parte interessadas (ex.: direção da escola, secretaria de educação e cultura etc.), além de orientar a organização das oficinas e, quando necessário, reorganizar as agendas de trabalho. Como metodologia para a realização das oficinas, organizou-se o esquema "Contextualização - Discussão - Prática - Avaliação", conforme a Figura 1.

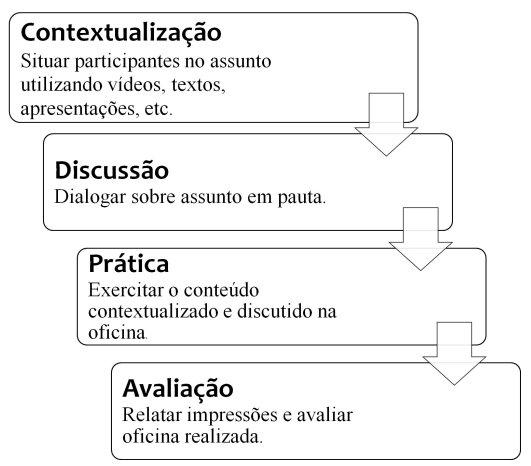

Figura 1. Metodologia aplicada nas oficinas.

O tema "Informática Acessível e Recursos de Tecnologia Assistiva", em especial, foi abordado junto a professores no mês de maio, na sala de recursos multifuncionais da escola. Após apresentação da sala, seus objetivos e os recursos disponíveis, os participantes expuseram suas opiniões, relatando suas experiências anteriores, ponderando avanços na área e os benefícios do uso da tecnologia. As atividades práticas envolveram o manuseio dos equipamentos e dos aplicativos disponíveis na sala de recursos.

\footnotetext{
${ }^{1}$ Disponível em: http://linuxeducacional.c3sl.ufpr.br/LE4/. Acessado em: Jul. 2013.
} 
No dia 24 de novembro de 2013, a experiência desenvolvida na escola foi relatada pelo bolsista e por uma professora no "V Workshop sobre Uso da Informática em Atividades de Ensino-Aprendizagem no Município de Alegrete" - ação conjunta com o projeto de extensão "Info.edu: Novos Talentos no Pampa" (Programa Novos Talentos / DEB / CAPES). Esse evento reuniu a equipe de elaboração e execução do projeto, representantes das comunidades escolares envolvidas, acadêmicos matriculados na disciplina "Acessibilidade e Inclusão Digital”, além de interessados em Informática na Educação.

\section{Resultados e Discussões}

O projeto atingiu satisfatoriamente os objetivos propostos, contribuindo à formação continuada de professores, organizando discussões e práticas sobre acessibilidade e recursos da informática acessível disponíveis na escola, favorecendo a inclusão digital de seus participantes. A realização do projeto na escola provocou o uso da informática em seu cotidiano, incentivando alguns professores a enriquecerem seu trabalho pedagógico com recursos da informática. Estudantes e participantes da comunidade beneficiaram-se de oficinas com temáticas diversificadas e atuais.

Embora tenham sido ofertadas 10 vagas para cada um dos grupos de participantes, houve baixa adesão às oficinas por professores e por membros da comunidade: dos sete professores inscritos, dois tiveram frequência suficiente nas oficinas; dos seis membros da comunidade inscritos, três tiveram frequência suficiente. Por outro lado, os estudantes indicaram maior interesse em participar, sendo alguns alocados às oficinas para membros da comunidade. Entretanto, dos 16 estudantes inscritos, apenas sete tiveram frequência suficiente nas oficinas. Em particular, para o grupo de professores, a carga-horária de 04 horas consecutivas de duração por encontro precisa ser revista em novas ofertas de oficinas nesta escola. No que se refere à participação da comunidade, a divulgação das oficinas deve ser mais bem trabalhada.

A avaliação realizada ao final de cada oficina forneceu feedback a curto prazo, permitindo - a partir das opiniões colhidas dos participantes - a realização de ajustes nas oficinas seguintes. Já a avaliação final do projeto deve subsidiar o desenvolvimento de novas ações de extensão.

Todos os participantes avaliaram a divulgação, os tópicos abordados e a pontualidade como excelente ou ótimo. Por outro lado, $18 \%$ dos participantes consideraram a infraestrutura do Laboratório de Informática da escola ruim e 55\% a consideraram péssima, indicando a necessidade de melhorar a manutenção da infraestrutura do Laboratório de Informática para que ele possa ser mais bem aproveitado, inclusive como ferramenta pedagógica. Neste aspecto, observa-se que, apesar dos esforços da direção da escola durante o período de desenvolvimento do projeto para que o laboratório de informática estivesse em ordem para uso dos extensionistas e pela comunidade escolar, o precário sistema de manutenção dos laboratórios tem levado a uma baixa adoção dos recursos da informática por professores.

\section{Considerações Finais}

Este artigo buscou apresentar um relato de experiência em uma das ações de extensão do Grupo de Estudos em Informática na Educação do Campus Alegrete da UNIPAMPA realizada, em 2012, no contexto do projeto "Info.edu: tecnologias da informação e 
comunicação em comunidades escolares de Alegrete" (MEC/SESu - PROEXT 2011). O relato enfocou a oferta de oficinas de informática - voltadas a professores, estudantes e comunidade - na EMEB Eurípedes Brasil Milano.

A realização do projeto nas escolas, com auxílio de bolsistas de cursos da área da Computação, provocou o uso mais frequente dos Laboratórios de Informática, tanto para a execução das oficinas quanto para o apoio a outras atividades de informática na educação desenvolvidas pelas escolas participantes. Aos bolsistas, o projeto possibilitou a experiência em atividades de extensão, o contato direto com a situação atual de uso das tecnologias digitais em escolas públicas, além da experiência no planejamento e na execução de oficinas de informática.

De forma participativa e dialética, através da extensão universitária, busca-se colaborar para que a acessibilidade e a inclusão digital ocorram na rede pública de ensino de Alegrete. Desafios existem e precisam ser abordados.

\section{Agradecimentos}

Ao Grupo de Estudos em Informática na Educação do Campus Alegrete da UNIPAMPA e participantes em suas ações. Ao grupo de pesquisa Tecnologia Social e Assistiva (TESA) do Campus Alegrete da UNIPAMPA. Ao MEC/SESu - PROEXT 2011, que financiou o projeto "Info.edu: tecnologias da informação e comunicação em comunidades escolares de Alegrete". Ao Programa Novos Talentos / DEB / CAPES, que financia o projeto "Info.edu: Novos Talentos no Pampa".

\section{Referências}

Amanda M. Melo, J. F. S. and Wernz, M. C. G. (2012). Desafios à pesquisa em computação em contexto educacional - qualidade no uso de objetos de aprendizagem em perspectiva. In Anais do DesafIE! SBC.

Melo, A. M. and Pupo, D. T. (2010). Livro Acessível e Informática Acessível. Ministério da Educação. $1^{\text {a }}$ Edição.

Michael. J. Muller, J. H. H. and Dayton, T. (1997). Participatory practices in the software lifecycle. In M. Helander, T. K. L. and Prabhu, P., editors, Handbook of HumanComputer Interaction. Elsevier.

Ministério da Educação. Programa Banda Larga na Escola. http://portal.mec.gov.br/index.php?option=com_content\&view=article\&id=15808:programabanda-larga-nas-escolas\&catid=193:seed-educacao-a-distancia. Julho 2013.

Ministério da Educação. Programa Nacional de Tecnologia Educacional (ProInfo). http://portal.mec.gov.br/index.php?Itemid=462. Julho 2013.

Ministério da Educação. Programa Um Computador por Aluno (UCA). http://www.uca.gov.br/institucional/. Julho 2013.

Secretaria da Educação do Estado do Rio Grande do Sul. Professores do ensino médio receberão tablets. http://www.educacao.rs.gov.br/pse/html/noticias_det.jsp?ID=10743. Publicação: 28 de dezembro de 2012.

Thiollent, M. J. M. (1996). Metodologia da Pesquisa-Ação. Cortez. 